\title{
ORIENTASI DAN POLA TANAM \\ PADA PENGGUNAAN LAHAN TEGALAN \\ DI KECAMATAN KLEDUNG KABUPATEN TEMANGGUNG
}

\author{
Oleh: \\ Valentina Arminah \\ Mahasiswa S3 Program Studi Geografi UGM \\ Staf Pengajar Sekolah Tinggi Pertanahan Nasional
}

\section{$\underline{\text { Abstrak }}$}

Pertanian lahan kering salah satunya berwujud tegal mempunyai potensi tinggi untuk mengatasi kekurangan pangan atau meningkatkan pendapatan. Luas dan potensi lahan tegal mempunyai prospek yang baik di masa yang akan datang dalam peningkatan hasil pertanian. Saat ini lahan tegal belum mendapatkan perhatian yang serius dibandingkan dengan lahan sawah, perkebunan, maupun tambak. Penelitian ini dilakukan di Kecamatan Kledung dengan tujuan mengkaji pemanfaatan lahan untuk usaha tani lahan tegalan terutama mengkaji penggunaannya yang terwujud pada sistem pola tanam. Pengumpulan data dilakukan dengan cara interpretasi peta dan observasi lapangan, dilengkapi dengan data monograii kecamatan. Penelitian ini memberikan hasil bahwa petani lahan kering di Kecamatan Kledung memanfaatkan lahan dengan baik dalam arti sepanjang tahun ditanami dengan cara mengusahakan berbagai jenis tanaman untuk memenuhi kebutuhan hidupnya dan dengan pola tanam yang menguntungkan petani.

Kata kunci : orientasi tanam, pola tanam

\section{Pendahuluan}

Tanah, atau dalam bahasa teknis sering disebut dengan lahan, merupakan karunia Tuhan Yang Maha Esa bagi Bangsa Indonesia untuk 
Orientasi dan Pola Tanam Pada Penggunaan Lahan Tegalan di Kecamatan Kledung Kabupaten Temanggung

kepentingan hajat hidup orang banyak baik tanah itu telah dimiliki atau dikuasai oleh seseorang maupun kelompok orang, maupun yang belum dimiliki atau dikuasai. Orang yang telah memiliki atau menguasai tanah berdasarkan peraturan perundang-undangan wajib menggunakan tanah sesuai dengan sifat dan tujuan haknya berdasarkan persediaan, peruntukan, penggunaan, dan pemeliharaannya. Hal ini dimaksudkan agar penggunaan tanah lestari dan berkelanjutan. Penggunaan tanah merupakan wujud tutupan muka bumi, baik yang terjadi karena proses alain maupun buatan manusia (PP No. 16 Tahun 2004).

Indonesia dikenal sebagai negara agraris, sebagian besar penduduknya tinggal di daerah pedesaan sebagai petani, baik petani lahan basah maupun lahan kering. Pertanian lahan kering umumnya diusahakan di daerah yang tidak subur, kekurangan air, atau daerah yang mempun yai kemiringan. Kemiringan tanah merupakan salah satu pertimbangan dalam penentuan jenis tanaman yang diusahakan pada lahan tegal. Penelitian terkait pengembangan pertanian lahan kering belum banyak dilakukan, sehingga pengelolaan lalian tegal menjadi kurang berkembang. Daerah penelitian terletak pada lereng Gunung Sumbing dan Sindoro, Jengan tingkat kecuraman mencapai lebih dari 40 persen, dan terletak pada dua bentang lahan yang berbeda sehingga dimungkinkan kondisi fisik tanahnya akan berbeda. Kondisi fisik tanah akan berpengaruh pada jenis penggunaan tanah dan jenis tanaman yang dapat diusahakan pada satu kawasan.

Daerah penelitian yang meliputi satu wilayah Kecamatan Kledung mempunyai jumlah penduduk sebanyak 25.518 jiwa yang terdiri dari 6.115 keluarga. Penduduk Kecamatan Kledung sebagian besar hidup sebagai petani yang sebagian besar merupakan petani lahan kering dan sebagian kecil petani lahan basah. Pertanian tanaman semusim pada lahan kering dilakukan hingga mencapai tanah dengan kemiringan yang tInggi. Daerah dengan kemiringan tinggi yang dimanfaatkan untuk usaha tani lahan kering sangat rentan terhadap erosi sehingga diperlukan orientasi dan sisten pola tanam yang tepat.

\section{Tinjauan Pustaka}

Tanah permukiman (top soil) merupakan bagian penting bagi tanaman dan kontrol degradasi tanah. Tanah permukiman dipengaruhi oleh beberapa faktor, antara lain iklim, vegetasi, topografi, mineral tanah, 
proses permukaan, biologi dalam tanah, dan manusia. Iklim berpengaruh langsung maupun tidak langsung pada tanah permukaan. Vegetasi berpengaruh pada tanah permukaan dari dampak jatuhan air hujan dan angin. Topografi berpengaruh pada kedalaman dan stabilitas tanah perm ıkaan. Kandungan mineral tanah berpengaruh terhadap pengembang kerutan tanah. Proses permukaan yang berpengaruh pada tanah permukaan adalah terjadinya erosi oleh angin dan air. Aktivitas biologi yang penting pada tanah permukaan adalah aktivitas cacing, rayap, dan semut. Pengaruh aktivitas manusia terhadap tanah permukaan, antara lain pestisida pada jangka pendek bermanfaat, tetapi dalam jangka panjang dapat menimbulkan masalah terutama bila dilakukan rotasi tanam, tanaman berikut dapat rusak, sedangkan penggunaan pupuk hijau dan kacang-kacangan dapat mengubah status nutrisi pada tanah permukaan, aktivitas pertambangan, polusi zat kimia melalui air hujan juga dapat merusak tanah permukaan (Management and Conversation, 1998).

Agus Andoko (2004) mengemukakan bahwa (1) Vertikultur merupakan satu teknik budidaya tanaman secara bertingkat sebagai upaya pemanfaatan lahan sempit seoptimal mungkin, dengan teknik ini populasi tanaman dalam satuan luas tertentu berlipat 3-10 kali dibanding teknik konvensional, tetapi investasi yang dibutuhkan jauh lebih tinggi dibandingkan dengan cara konvensional, bila digunakan pupuk organik akan aman bagi lingkungan; (2) Pertanian organik merupakan teknik budidaya tanaman yang raman lingkungan dengan ciri utama menghindari penggunaan pupuk dan pestisida sehingga aman bagi lingkungan dan hasil tanaman sehat untuk dikonsumsi; (3) Budidaya silvikultur organik merupakan cara budidaya untuk mengoptimalkan lahan sempit tetapi memberikan hasil yang bebas residu pestisida kimia yang berbahaya.

Pengelolaan sistem lingkungan hidup harus dilakukan dengan tiga cara, cara pertama menggunakan instrumen pengaturan dan pengawasan, tujuannya adalah untuk mengurangi pilihan pelaku dalam usaha pemanfaatan lingkungan hidup, contohnya pelarangan kegiatan yang merusak lingkungan dan mengawasi kepatuhan pelaksanaannya. Cara kedua dengan instrumen ekonomi tujuannya mengubah nilai untung terhadap rugi bagi pelaku. Instrumen yang ketiga dengan cara persuasif, yaitu mendorong masyarakat mengubah persepsi manusia dan lingkungan hidup. Manusia diajak untuk mencintai lingkungan hidup dan memeliharanya dengan baik karena ada nilai yang tidak terbayarkan 
Orientasi dan Pola Tanam Pada Penggunaan Lahan Tegalan di Kecamatan Kledung Kabupaten

Temanggung

dengan uang bila terjadi pengrusakan lingkungan. Pengetrapan atur diri ser:diri bertumpu pada inisiatif dan inovasi masyarakat untuk mengelola lingkungannya secara adaptif (Sumarwoto, 2001). Usaha tani di lahan tegal dengan pola tanam dan jenis tanaman yang berbeda berarti penanaman dilakukan terus-menerus sepanjang musim, dengan demikian lahan tegalan ikut berperan dalam menjaga lingkungan. Pada lahan tegalan tanah tetap tertutup vegetasi sehingga tidak mudah tererosi, dengan demikian stabilitas produksi dan pendapatan petani dapat terjamin dan berkelanjutan.

Penanaman tanaman pada lahan tegalan perlu memperhatikan jenis tanaman dan pola tananınya. Kombinasi jenis tanaman yang hasilnya dibutuhkan atau laku dijual merupakan keharusan bagi petani yang menggantungkan hidupnya dari hasil pertanian. Kebutuhan petani clapat terpenuhi dari hasil kombinasi berbagai jenis tanaman, seperti padi, palawija, tembakau, sayur-sayuran, tanaman pakan ternak, buah-buahan, maupun tanaman industri. Pola tumpang sari atau tanam ganda pada lahan tegalan dapat secara tumpang sari pada lahan yang lues, tumpang sari perbedengan, penanaman campuran (mixed cropping), tumpang sari seumur (inter cropping), relay cropping, inter culture, lokasi tanam, dan sistem lorong (Wani Hadi Utomo, 1989, Anonim, 1997).

\section{Metode Penelitian}

Penelitian ini bersifat deskriptif. Data yang dikumpulkan berupa data primer dan sekunder. Data primer antara lain jenis tanaman, pola tanam, dan konservasi lahan, sedangkan data sekunder yang dikumpulkan antara lain kemiringan tanah. Pengurnpulan data dilakukan dengan cara interpretasi peta, observasi lapangan, dan pengambilan data monografi kecamatan. Analisis data dilakukan dengan analisis deskrlptif.

\section{Hasil dan Pembahasan}

Kecamatan Kledung merupakan salah satu kecamatan di Kabupaten Temanggung yang terletak berbatasan dengan Kabupaten Wonosobo, mempunyai luas secara keseluruhan 3.221,32 Ha dan terbagi menjadi 13 desa dengan ibukota kecamatan terletak di Desa Kledung. Jarak dari ibukota Kecamatan Kledung ke ibukota Kabupaten Temanggung adalah $22 \mathrm{Km}$. Secara administrasi, Kecamatan Kledung sebelah utara berbatasan dengan Kecamatan Bansari, sebelah timur berbatasan dengan 
Kecamatan Bulu, sebelah selatan dan barat berbatasan dengan Kabupaten Wonosobo.

\section{Penduduk}

Penduduk dapat merupakan potensi, tetapi juga dapat merupakan beban dalam memanfaatkan lahan. Penduduk merupakan potensi apabila memberikan hasil dan meningkatkan kesejahteraan dalam pemanfaatan lahan, dan merupakan beban apabila justru merusak lingkungan.

Nama dan luas desa, jumlah penduduk, jumlah keluarga, dan kepadatan penduduk Kecamatan Kledung disajikan pada tabel 1.

Tabel 1. Nama dan Luas Desa, Jumlah Penduduk, Jumlah Keluarga serta Kepadatan Penduduk di Kecamatan Kledung

\begin{tabular}{|c|l|r|r|r|c|}
\hline No. & \multicolumn{1}{|c|}{ Nama Desa } & Luas $(\mathrm{Ha})$ & $\begin{array}{c}\text { Jumlah } \\
\text { Pddk } \\
\text { (Jiwa) }\end{array}$ & \multicolumn{1}{|c|}{$\begin{array}{c}\text { Jumlah } \\
\text { keluarga } \\
\text { (KK) }\end{array}$} & $\begin{array}{c}\text { Kepadatan } \\
\text { Penduduk } \\
\text { (Jiwa/Ha) }\end{array}$ \\
\hline 1. & Batursari & 149,28 & 1.695 & 355 & 11 \\
\hline 2. & Tlahap & 400,00 & 3.822 & 814 & 10 \\
\hline 3. & Jaketro & 208,26 & 1.118 & 302 & 5 \\
\hline 4. & Kwadungan Jurang & 197,95 & 1.028 & 274 & 5 \\
\hline 5. & Kivadungan Gunung & 239,80 & 1.932 & 451 & 8 \\
\hline 6. & Canggal & 101,00 & 450 & 110 & 4 \\
\hline 7. & Kalirejo & 65.28 & 911 & 226 & 14 \\
\hline 8. & Paponan & 79,27 & 1.540 & 418 & 19 \\
\hline 9. & Kruwisan & 317,76 & 2.195 & 595 & 7 \\
\hline 10. & Kledung & 336,48 & 2.452 & 626 & 7 \\
\hline 11. & Petarangan & 467,43 & 3.639 & 907 & 8 \\
\hline 12. & Janibu & 75,86 & 894 & 191 & 12 \\
\hline 13. & Tuksari & 583,00 & 3.832 & 846 & 7 \\
\hline & Jumlah & 3.221 .32 & 25.518 & 6.113 & 8 \\
\hline
\end{tabular}

Sumber: Kantor Kecamatan Kledung Tahun 2004

Dari tabel diatas dapat dilihat bahwa Desa Kalirejo, Desa Jambu, dan Jesa Paponan termasuk desa yang luas wilayahnya sempit jika dibandingkan desa-desa lainnya di Kecamatan Kledung, sedangkan Desa Tuksari merupakan desa yang paling luas wilayahnya. Kepadatan penduduk di setiap desa di Kecamatan Kledung dapat dikatakan masih rendah. Desa yang terpadat penduduknya adalah Desa Paponan. 
Orientasi dan Pola Tanam Pada Perggumaan Lahan Tegalan di Kecamatan Kledung Kabupaten

Temanggung

Kepadatan penduduk merupakan salah satu indikator kualitas lingkungan, semakin padat penduduk umumnya semakin buruk kondisi lingkungannya.

Iklim

Data iklim sangat berpengaruh terhadap aktivitas pertanian, terutama suhu dan curah hujan. Data curah hujan bermanfaat sebagai data dasar prediksi usaha tani tanaman semusim pada tahun-tahun herikutnya. Kondisi jumlah curah hujan dan hari hujan selama 5 tahun di Kecamatan Kledung yang terletak pada ketinggian 800 hingga lebih dari 2.000 meter dari permukaan air laut dan dengan lereng hingga mencapai lebih dari 40\% adalah seperti tabel 2.

Tabel 2. Jumlah Curah Hujan dan Hari Hujan di Kecamatan Kledung Tahun 2000-2004

\begin{tabular}{|c|l|c|c|c|c|c|c|c|c|c|c|c|c|}
\hline \multirow{2}{*}{ No. } & \multirow{2}{*}{ Bulan } & \multicolumn{2}{|c|}{2000} & \multicolumn{2}{|c|}{2001} & \multicolumn{2}{c|}{2002} & \multicolumn{2}{c|}{2003} & \multicolumn{2}{|c|}{2004} & \multicolumn{2}{|c|}{ Rata-Rata } \\
\cline { 3 - 16 } & $\begin{array}{c}\mathrm{CH} \\
(\mathrm{mm})\end{array}$ & $\mathrm{HH}$ & $\begin{array}{c}\mathrm{CH} \\
(\mathrm{mm})\end{array}$ & $\mathrm{HH}$ & $\begin{array}{c}\mathrm{CH} \\
(\mathrm{mm})\end{array}$ & $\mathrm{HH}$ & $\begin{array}{c}\mathrm{CH} \\
(\mathrm{mm})\end{array}$ & $\mathrm{HH}$ & $\begin{array}{c}\mathrm{CH} \\
(\mathrm{mm})\end{array}$ & $\mathrm{HH}$ & $\begin{array}{c}\mathrm{CH} \\
(\mathrm{mm})\end{array}$ & $\mathrm{HH}$ \\
\hline 1. & Januari & 484 & 24 & 199 & 19 & 156 & 15 & 232 & 13 & 203 & 14 & 255 & 17 \\
\hline 2. & Februari & 288 & 19 & 122 & 16 & 149 & 28 & 276 & 23 & 295 & 22 & 226 & 22 \\
\hline 3. & Maret & 330 & 26 & 556 & 20 & 96 & 13 & 161 & 15 & 187 & 16 & 266 & 18 \\
\hline 4. & April & 148 & 10 & 309 & 17 & 92 & 6 & 419 & 20 & 311 & 19 & 256 & 14 \\
\hline 5. & Mel & 99 & 6 & 76 & 5 & 92 & 6 & 133 & 11 & 147 & 13 & 109 & 8 \\
\hline 6. & Juni & 27 & 3 & 94 & 6 & 128 & 14 & 83 & 4 & 92 & 6 & 85 & 7 \\
\hline 7. & Juli & 5 & 1 & 0 & 0 & 126 & 11 & 30 & 3 & 11 & 2 & 38 & 4 \\
\hline 8. & Agustus & 30 & 4 & 97 & 3 & 1 & 1 & 0 & $(1$ & 0 & 0 & 26 & 2 \\
\hline 9. & September & 10 & 2 & 114 & 6 & 14 & 6 & 22 & 2 & 9 & 2 & 39 & 4 \\
\hline 10. & Oktober & 131 & 12 & 312 & 16 & 397 & 21 & 23 & 6 & 18 & 5 & 176 & 12 \\
\hline 11. & November & 363 & 18 & 187 & 18 & 283 & 19 & 188 & 15 & 152 & 11 & 235 & 14 \\
\hline 12. & Desember & 246 & 24 & 204 & 12 & 191 & 14 & 304 & 19 & 294 & 21 & 248 & 18 \\
\hline & Jumlah & 2191 & 146 & 2281 & 151 & 1725 & 154 & 1871 & 131 & 1619 & 131 & 1937 & 143 \\
\hline
\end{tabular}

Sumber: Cabang Dinas Pertanian Kledung

Rata-rata jumlah curah hujan di Kecamatan Kledung sekitar 2000 $\mathrm{mm} /$ tahun dan rata-rata hari hujan sekitar 145 hari/tahun. Bulan Juli dan bulan Agustus merupakan bulan-bulan yang paling kering, bahkan pada bulan tersebut sering tidak ada hujan sama sekali.

Iklim sangat berperan bagi petani antara lain terkait dengan waktu penanaman, sebagai contoh tanaman tembakau sangat baik ditanam menjelang musim kemarau karena tanaman tembakau muda hingga saat panen tidak perlu air, tetapi tanaman sayuran seperti kubis, wortel, dan bawang merah baik ditanam saat musim hujan sebab tanaman tersebut perlu banyak air. 


\section{Bentuk Penggunaan Lahan dan Pola Tanam}

Penggunaan lahan merupakan cerminan aktivitas manusia pada sebidang lahan dan penggunaan lahan berbeda dari satu tempat ke tempat lain sesuai kondisi fisik alamnya. Daerah penelitian yang terletak di lereng gunung mempunyai variasi jenis penggunaan lahan antara lain permukiman, sawah, tegalan, dan hutan. Rincian penggunaan lahan pada masing-masing desa di Kecamatan Kledung dapat dicermati pada tabel 3.

Tabel 3. Jenis dan Luas Penggunaan Lahan Masing-Masing Desa di Kecâmatan Kledung

\begin{tabular}{|c|c|c|c|c|c|c|c|c|}
\hline \multirow[t]{2}{*}{ No. } & \multirow[t]{2}{*}{ Nama Desa } & $\begin{array}{l}\text { Luas } \\
\text { Desa }\end{array}$ & $\begin{array}{l}\text { Pemu- } \\
\text { kiman }\end{array}$ & Sawah & Tegalan & $\begin{array}{l}\text { Hutan } \\
\text { Rakyat }\end{array}$ & $\begin{array}{l}\text { Hutan } \\
\text { Negara }\end{array}$ & $\begin{array}{l}\text { Lain- } \\
\text { lain }\end{array}$ \\
\hline & & $\mathrm{Ha}$ & $\mathrm{Ha}$ & $\mathrm{Ha}$ & $\mathrm{Ha}$ & $\mathrm{Ha}$ & $\mathrm{Ha}$ & $\mathrm{Ha}$ \\
\hline 1. & Batursari & 149,28 & 9,30 & - & 112,25 & $\sim$ & 25,00 & 2,23 \\
\hline 2. & Tlahap & 400,00 & 11,00 & - & 259,00 & 51 & 72,00 & 6,00 \\
\hline 3. & Jaketro & 208,26 & 5,38 & 27 & 114,38 & - & 65,00 & 0,50 \\
\hline 4. & $\begin{array}{l}\text { Kwadungan } \\
\text { Jurang }\end{array}$ & 197,95 & 5,00 & 12 & 120,00 & - & 61,00 & 0,45 \\
\hline 5. & $\begin{array}{l}\text { Kwadungan } \\
\text { Gunung }\end{array}$ & 239,80 & 10,45 & - & 138,72 & - & 90,00 & 0,63 \\
\hline 6. & Canggal & 101,00 & 10,00 & - & 75,50 & - & 15,00 & 0,20 \\
\hline 7. & Kalirejo & 65,28 & 5,79 & 59 & - & - & - & 0,49 \\
\hline 8. & Paponan & 79,27 & 8,91 & 70 & - & - & - & 1,36 \\
\hline 9. & Kruwisan & 317,76 & 9,60 & " & 272,18 & - & 35,00 & 0,73 \\
\hline 10. & Kledung & 336,48 & 12,63 & . & 329,00 & - & 80,00 & 14,20 \\
\hline 11. & Petarangan & 467,43 & 15,91 & 36 & 374,52 & - & 38,00 & 3,00 \\
\hline 12. & Jambu & 75,86 & 9,53 & - & 30,45 & 25 & 10,00 & 1,21 \\
\hline 13. & Tuksari & 583,00 & 24,00 & 43 & 319,00 & - & 190,00 & 2,00 \\
\hline & Jumlah & $3.221,32$ & 138,00 & 247 & 2.046 .20 & 76 & 681,00 & 33,00 \\
\hline
\end{tabular}

Dari tabel 3, dengan jelas dapat diketahui bahwa pertanian tegal menempati lahan yang paling luas, yaitu 2.046,20 Hektar atau 63,52\% dari seluruh wilayah Kecamatan Kledung. Hutan menempati urutan kedua, yaitu seluas 681,0 Hektar atau $21,14 \%$. Pertanian sawah menempati sebagian kecil dari Desa Jaketro, Kwadungan Jurang, Kalirejo, Paponan, Petarangan, dan Tuksari dengan memanfaatkan irigasi sederhana. Permukiman umumnya terdiri dari bangunan-bangunan yang sifatnya permanen dan berada di sepanjang jalan raya yang menghubungkan Kota Temanggung dan Wonosobo, berlokasi di lereng bawah hingga lereng tengah bagian bawah dengan pola umumnya mengelompok.

Pertanian tegal yang terletak di lereng gunung dan menempati lahan terluas di daerah penelitian merupakan sumber penghasilan pokok bagi sebagian besar peinduduk di Kecamatan Kledung. Tanaman unggulan 
di Kecamatan Kledung adalah tembakau. Jenis tembakau yang harganya mahal disebut tembakau srintil dan tembakau jenis ini pernah mengalami kejayaan tahun 1980 hingga 1982. Tembakau srintil dihasilkan dari la'.7an tegal di lereng atas. Tanaman semusim lain yang ditanam di daerah penelitian, antara lain jagung, kacang merah, kentang, bawang rnerah, bawang putih, koro, tomat, terong, ketela pohon, dan rumput gajah.

Petani tembakau mengalami keterpurukan antara tahun 2002 hingga 2005 karena harga tembakau merosot tajam disebabkan pergantian musim yang tidak sesuai dengan harapan petani. Pada saat itu harga tembakau hanya mencapai harga Rp 15.000,- per kilogram. Pada tahun 2006 harga tembakau dapat terangkat lagi, bahkan tembakau yang mutunya baik dapat mencapai harga antara Rp 80.000,- per kilogram hingga Rp 115.000,- per kilogram. Setelah menanam tembakau, petani menanam jagung atau menanam tanaman semusim lain untuk mencukupi kebutuhan hidup. Penanaman tanaman semusim dilakukan dengan tanaman tunggal atau dikombinasikan dengan tanaman semusim yang lain.

Petani di seluruh Desa Canggal pernah mempunyai niat apabila pada tahun tanam tembakau tahun 2006 harganya masih terpuruk, mereka berorientasi pindah ke tanaman hortikultura atau tanaman sayuran dan rumput gajah untuk menghidupi ternak mereka.

\section{Pola Tanam}

Penanaman tanaman pada lahan tegalan di daerah penelitian dilakukari dengan tanaman tunggal atau tumpang sari. Pola tanam tumpang sari atau pola tanam ganda dilakukan untuk mengatasi kegagalan panen pada salah satu jenis tanaman. Pola tanam tunggal jika sebidang tanah hanya ditanami dengan satu jenis tanaman dan pola tanam ganda jika ditanami lebih dari satu jenis tanaman. 


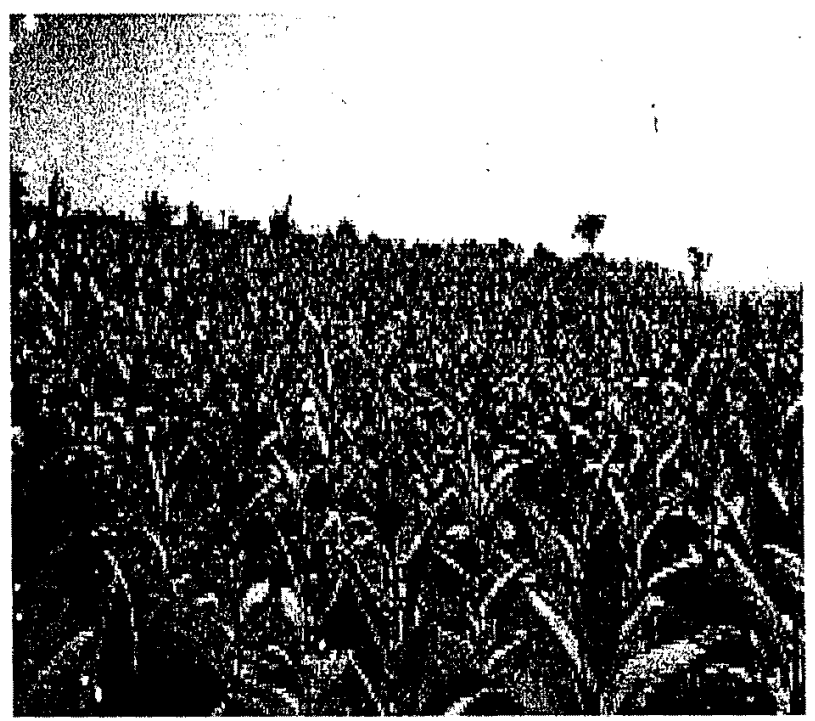

Gambar 1. Pola Tanam Tunggal Tembakau

Pola tanam tunggal dilakukan pada sebidang tanah yang luas dan hanya ditanami dengan satu jenis tanaman, seperti gambar 1 di atas yang memperlihat'kan pola tanam tunggal dengan satu jenis tanaman yaitu tembakau. Pola tanam tunggal dapat memberi keuntungan yang besar, terutama jika saat panen harga jualnya tinggi. Harga tembakau pada musim panen tahun 2006 mengalami kenaikan signifikan, sehingga petani sangat diuntungkan dengan sistem tanam tunggal ini.

Pola tanam tumpang sari yang diusahakan di daerah penelitian antara lain:

1. Tumpang sari seumur (inter cropping)

Tumpang sari seumur apabila dua jenis tanaman atau lebih ditanam secara serentak dan membentuk larikan. Contoh tumpang sari seumur yang dilakukan di daerah penelitian adalah tumpang sari tanaman tembakau dan kacang merah. 


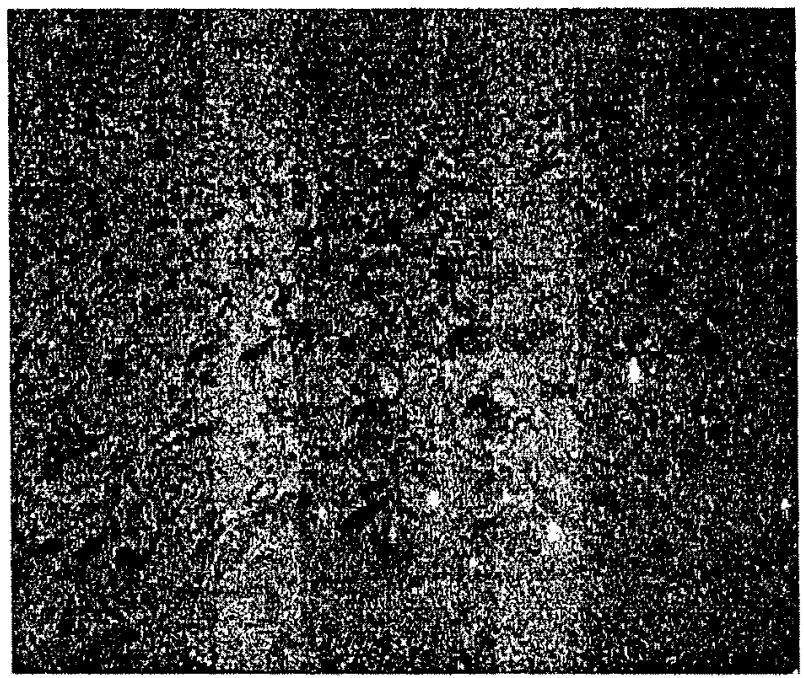

Gambar 2. Pola Tanam Tumpang Sari Seumur

Tanaman dengan pola tumpang sari seumur pada gambar 2 adalah tanaman tembakau yang ditanam bersamaan waktunya dengan tanaman kacang merah. Dengan pola tanam tumpang sari seumur, satu kali musim tanam petani bisa mendapatkan hasil lebih dari satu macam komoditi, dan sebelum tembakau dapat dipanen, tanaman kacang kacang merah sudah lebih dulu mulai dapat dipetik hasilnya.

2. Inter Culture

Pada pola tanam ini, tanaman semusim ditanam diantara tanaman tahunan. Contoh pola tanam inter culture yang dilakukan di daerah penelitian adalah tanaman tembakau dikombinasi dengan tanaman kopi. 


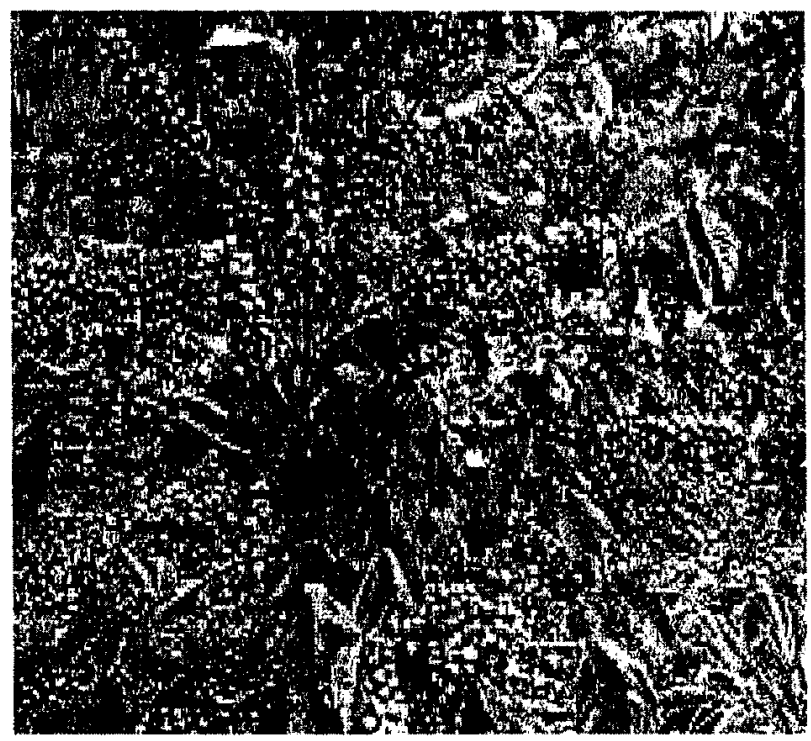

Gambar 3. Pola Tanam Inter Culture

Pada gambar 3 tampak dengan jelas tanaman tembakau masih berumur pendek, tetapi tanaman kopi buahnya tampak begitu lebat. Tanaman kopi dapat dipanen sepanjang tahun walaupun tanaman tembakaunya sudah habis dipanen.

3. Penanaman Campuran (Mixed Cropping)

Pola tanam campuran yaitu jika lahan ditanami dua atau lebih jenis tianaman dengan sebaran tidak beraturan dan ditanam pada waktu yang sama. 
Orientasi dan Pola Tanam Pada Penggunaan Lahan Tegalan di Kecamatan Kledung Kábupaten Temanggung

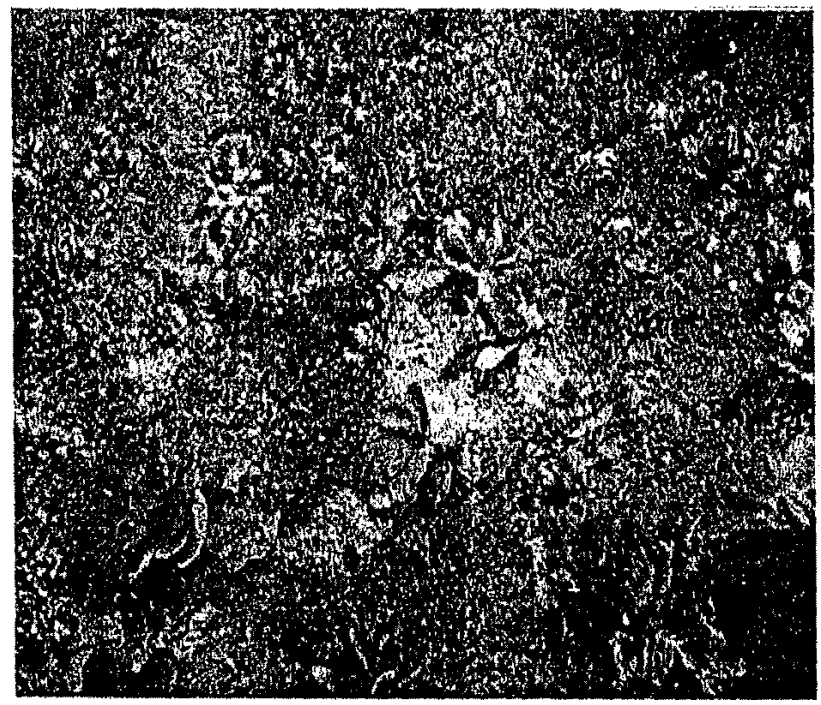

Gambar 4. Pola Tanam Mixed Cropping

Gambar 4 menunjukkan bahwa petani berusaha menanam 3 macam tanaman semusim yaitu kubis, tembakau dan cabe. Ini dilakukan dengan maksud dalam satu kali tanam bisa mendapatkan hasil 3 komoditi dengan waktu panen yang tidak bersamaan, disamping untuk mengatasi apabila salah satu komoditi mengalami kegagalan panen atau harga sedang mengalami penurunan.

1. Tumpang Sari Eeda Umur (Inter Planting)

Inter planting adalah pola tanam dengan kombinasi jenis tanaman berumur pendek dan tanaman lain yang berumur lebih panjang pada sebidang tanah yang sama. 


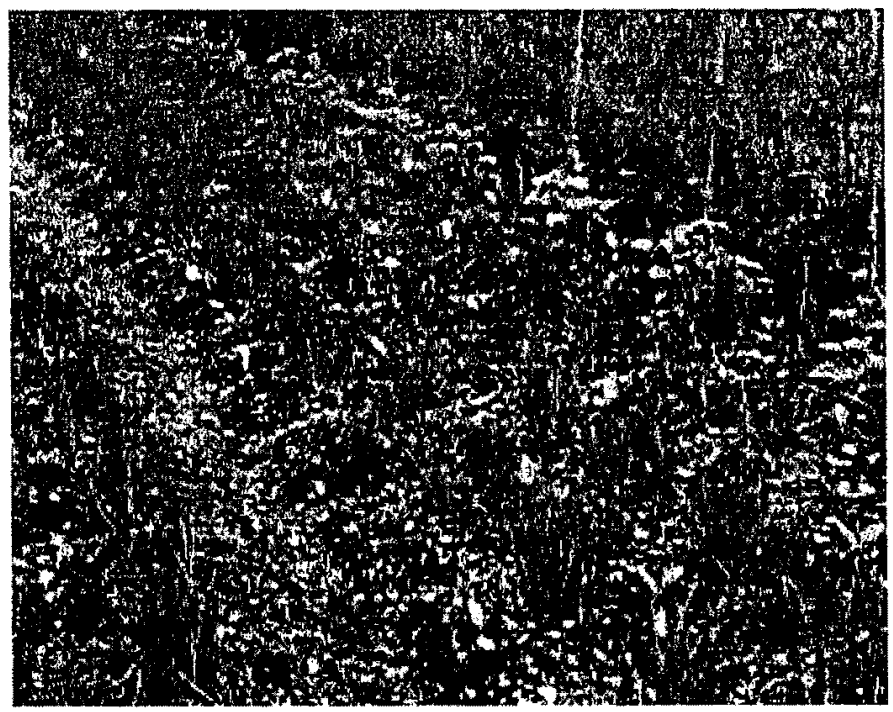

Gambar 5. Pola Tanam Inter Planting

Pola tanam inter planting pada gambar 5 adalah kombinasi tanaman bawang merah, buncis, dan tembakau. Tanaman tembakau berumur lebih panjang daripada tanaman bawang merah dan buncis, setelah bawang merah dan buncis habis dipanen, petani masih punya harapan panen tembakau sehingga penghasilan mereka berkelanjutan.

\section{Penutup}

1. Pemanfaatan lahan tegal tergantung pada musim, saat musim kemarau petani berorientasi pada tanaman tembakau sebagai tanaman unggulan di daerah penelitian, sedangkan saat musim hujan petani berorientasi pada tanaman semusim lain terutama sayur-sayuran.

2. Berbagai pola tanam diterapkan para petani, baik pola tanam tunggal maupun pola tanam ganda. Penerapan pola tanam ganda dimaksudkan untuk menyiasati bila terjadi kegagalan panen pada salah satu jenis tanaman dan untuk mendapatkan produktifitas yang berkelanjutan. 


\section{Daftar Pustaka}

Agus Andoko. 2004. Budidaya Cabe Merah Secara Vertikultur Organik. Penebar Swadaya.

Anonim. 1997. Mengelola Lahan Tegalan. Tim Penulis Pusat Pendidikan Lingkungan Hidup Seloliman. Trubus Agrisarana.

Anonim. 1998. Top Soil Characterization for Sustainable Land Management. Roma: Land and Water Development Division Soil Resourses, Management and Conservation.

Sumarwoto. 2001. Atur Dirl Sendiri Paradigma Baru Pengeloiaan Lingkungan Hidup. Yogyakarta: Gadjah Mada Press.

Wani Hadi Utomo. 1989. Konservasi Tanah di Indonesia Suatu Rekaman dan Analisa. Malang: Universitas Brawijaya. 